\title{
Association of pentraxin 3 with atherosclerotic cardiovascular diseases - general knowledge in 2018
}

\section{ABSTRACT}

Pentraxin 3 (PTX3), an acute phase protein, contrary to C-reactive protein (CRP), is produced locally, where the inflammation takes place, for example in the endothelium. It is not clearly known whether the inflammatory factors are the cause of atherosclerosis or only indicators of vascular inflammation. It is still not known what is the role of PTX in the natural history of atherosclerosis - protection or promotion. It was established that the elevated plasma concentration of PTX is related to the occurrence of cardiovascular events caused by atherosclerosis, including myocardial infarction (MI), decreased 3-months survival after MI, unstable angina or heart failure. On the other hand, PTX is suspected to play a protective role in the ischemic cardiac muscle. Therefore, if confirmed in trials, PTX3 could be administered during acute coronary syndrome. PTX3 might in the future become useful in assessing prognosis for patients with cardiovascular diseases and choosing the best therapeutic option for them. (Clin Diabetol 2018; 7, 4: 203-206)

Key words: pentraxin, atherosclerosis, cardiovascular diseases

Address for correspondence: dr n. med. Katarzyna Nabrdalik Katedra i Klinika Chorób Wewnętrznych, Diabetologii i Nefrologii, Śląski Uniwersytet Medyczny Wydział Lekarski z Oddziałem Lekarsko-Dentystycznym ul. 3 Maja 13-15, 41-800 Zabrze Phone: +48323704 415

e-mail: knabrdalik@yahoo.com

Translation: lek. Małgorzata Kamińska

Clinical Diabetology 2018, 7, 4, 203-206

DOI: $10.5603 /$ DK.2018.0015

Received: 03.05.2018 Accepted: 05.06.2018

\section{Introduction}

It is known that immune and inflammatory processes play a fundamental role in the development of atherosclerosis from the start of vascular endothelial damage until the time of acute clinical manifestation $[1,2]$. In the endothelium damaged by the inflammatory process, recruitment of neutrophils, macrophages, platelets, lymphocytes or previously activated myocytes occurs [3,4]. These cells, in response to endothelial damage, secrete a number of cytokines and proteins responsible for the initiation or intensification of inflammation $[3,4]$. Atherosclerosis, which is considered a chronic inflammatory process of the arterial wall, ultimately leads to formation of atherosclerotic plaques consisting of a fibrous cap made of collagen fibers and smooth muscle cells, a lipid core and infiltrates of inflammatory cells [3]. It is not known whether inflammatory proteins are causative factors in the pathogenesis of atherosclerosis, or are just indicators of the ongoing inflammatory process of the vessel. In recent years, researchers have been interested in pentraxin 3 (PTX3), a protein found in many cells in the vascular wall, and its potential relationship with cardiovascular diseases resulting from it $[4,5]$. The increase in plasma PTX3 concentration was associated with the risk of various cardiovascular events of atherogenic etiology, including myocardial infarction [6], unstable angina [7], increased 3-month mortality after myocardial infarction [8] or heart failure [9], but on the other hand its potential antiatherosclerotic effect has also been discussed [10].

This article summarizes the studies assessing the role of PTX3 in cardiovascular diseases caused by atherosclerosis.

\section{Pentraxin 3}

Pentraxins are a group of acute phase proteins, components of the complement system, which are 
the basic elements of innate humoral immunity. The pentraxin superfamily is characterized by presence of the following amino acid sequence in the C-terminal fragment: histidine-x-cysteine-serine/threonine-tryptophan- $x$-serine, where $x$ is any amino acid [11]. Depending on the length of the $\mathrm{N}$-terminal peptide chain, these proteins are divided into two groups: short- and long-chain pentraxins [12]. The first group includes biomarkers that are widely used in clinical practice: C-reactive protein (CRP) and serum amyloid $P(S A P)$. C-reactive protein is the first pentraxin which has been discovered. It is synthetized mainly in the liver and its production is influenced by proinflammatory cytokines. Pentraxin 3, described for the first time in 1992 by Breviaro et al., belongs to the long-chain pentraxins, like pentraxin 4, neuronal pentraxin 1 and neuronal pentraxin 2, and is made up of 381 amino acids. PTX3 gene is located on the chromosome 3 and organized in 3 exons encoding the leader peptide, $\mathrm{C}$-terminal domain and long $\mathrm{N}$-terminal domain of the protein [13]. The secondary, spiral structure of the $\mathrm{N}$-terminus, stabilized by disulfide bridges, is composed of four alpha-helices connected by short loops, while in the C-terminal fragment, the hydrophobic core is made up of two antiparallel beta-pleated. C- and N-terminal fragments are connected by disulfide bridges between the cysteines at positions 179 and 357 and form one protein monomer, and the PTX3 molecule, weighing $440 \mathrm{kDa}$, consists of 8 such monomers [14]. Pentraxin 3 , unlike CRP, is produced locally by vascular endothelial cells, fibroblasts, myeloid dendritic cells, macrophages, monocytes, adipocytes, synovial cells, chondrocytes and vascular smooth muscle cells, and its secretion is influenced by mediators such as interleukin 1 beta (IL1 $\beta$ ), tumor necrosis factor alpha (TNF $\alpha$ ), lipopolysaccharides (LPSs), as well as oxidized low-density lipoproteins (oxyLDLs) and occurs in the presence of some microorganisms (several Gram-positive and Gram-negative bacteria and fungi, including $A$. fumigatus and $P$. brasiliensis, as well as viruses, including cytomegalovirus [CMV] and influenza type $A$ viruses) $[5,15,16]$. In addition to the local production of pentraxin in response to an inflammatory stimulus, a certain amount of this protein is stored in neutrophil granules to be released into the extracellular space in the phase of acute inflammation [17]. Factors that inhibit pentraxin production include: interferon $\gamma$, interleukin 4 and 13, vitamin D3, and prostaglandin E2. Its concentration dynamically increases and correlates with the severity of the disease in cardiovascular diseases, infections, some cancers and autoimmune diseases [6].

Pentraxins play a key role in the non-specific immune response [18]. Increased concentration of PTX3 in inflammation may result from the mechanism of its action. The PTX3 function is to bind the complement component $\mathrm{C} 1 \mathrm{q}$ and to remove immune complexes from the body by activating the complement system via IgG-dependent classical pathway [9]. Binding of PTX3 with the complement component C1q results in activation of the complement cascade, attachment of $\mathrm{C} 1 \mathrm{r}$ and $\mathrm{C} 1 \mathrm{~s}$ complements and activation of $\mathrm{C} 1$ and $\mathrm{C3}$ convertase complexes [19].

\section{Pentraxin 3 and cardiovascular diseases caused by atherosclerosis}

Pentraxin 3 is considered a specific marker of local inflammation in the vascular wall $[5,20]$. The presence of PTX3 has been revealed in atherosclerotic lesions, and its concentration is higher in people with more advanced atherosclerosis [21-23]. In addition, PTX3 is considered to be a more sensitive biomarker of atherosclerotic plaque lesion compared with high sensitive (hs)-CRP [24]. The last stage of atherosclerosis leading to acute coronary syndrome is destabilization of the plaque and its rupture, and a significant correlation with elevated PTX3 concentration has been demonstrated at this stage [24]. In patients with stable ischemic heart disease, high PTX3 plasma concentration was associated with a $50 \%$ increase in the risk of acute coronary syndrome and an $80 \%$ increase in the risk of total mortality [25]. It was also emphasized that PTX3 may be an early marker of myocardial injury in acute coronary syndromes $[22,26]$. In patients with acute coronary syndrome and heart failure, the concentration of PTX3 significantly increases (an increase occurs after $6-8$ hours, and normalization - after 3 days) and positively correlates with the increase in T-troponin and creatine kinase. It is suggested that elevated PTX3 concentration may be an important prognostic factor of 3-months mortality after the onset of acute coronary syndrome [8]. Kimura et al. conducted a study in a group of patients treated with percutaneous coronary intervention due to ST-segment elevation myocardial infarction and showed that the elevated concentration of PTX3 was associated with the occurrence of a fibrous cap and impaired myocardial perfusion after revascularization, which is an unfavorable prognostic factor [29]. In the group of patients with myocardial infarction without ST-segment elevation treated with primary coronary angioplasty, it was shown that patients with elevated plasma PTX3 concentration have a significantly higher risk of early death (up to 30 days). In addition, this group of patients significantly more often have other unfavorable prognostic factors diabetes, kidney disease, hypertension, and reduced left ventricular ejection fraction. In these patients, 
a significant relationship between PTX3 and C-reactive protein, $\mathrm{N}$-terminal $\mathrm{B}$-type natriuretic propeptide and troponin $\mathrm{T}$ was also demonstrated, and elevated baseline concentration of PTX3 correlated with a higher incidence of subsequent cardiovascular events [28]. Contrary results obtained by Miyazaki et al. in a 5-year follow-up of over 4,000 patients in the Cholesterol and Recurrent Events (CARE) study, failed to confirm that PTX3 was a predictor of reoccurrence of cardiovascular events among patients after a coronary incident [29].

The plasma concentration of PTX3 is also significantly elevated in patients with heart failure, even with normal ejection fraction, and patients without heart failure with left ventricular diastolic dysfunction. In the study performed on 360 patients with heart failure and normal ejection fraction, Matsubara et al. proved that higher plasma PTX3 concentration correlates with the more frequent occurrence of cardiovascular events [30].

Moreover, it has been revealed several years ago that in the group of healthy adults, the plasma concentration of PTX3 is associated with cardiovascular risk factors, subclinical cardiovascular disease, coronary calcifications and cardiovascular events. This relationship has not been demonstrated for CRP, which indicates that PTX3 reflects other aspects of atherosclerosisrelated inflammation than $\mathrm{C}$-reactive protein, and that further research may provide additional data on atherosclerosis development and progression besides information on previously established markers of inflammation [26].

However, there are some controversies about the role of PTX3 in atherosclerosis. On the one hand, it is believed that this protein is involved in the process of atherosclerotic plaque formation [5], may contribute to plaque enlargement [21], and by increasing the secretion of the tissue factor, participate in the activation of blood clotting and thrombosis [31]. On the other hand, Norata et al. demonstrated in a study on mice devoid of PTX3-encoding gene that PTX3 deficiency contributes to the increase in the production of proinflammatory factors and the severity of inflammation within the vascular wall and that this protein has protective effect against atherosclerosis [32]. Similar findings were reported in human studies by Slusher et al. who observed an anti-inflammatory effect of PTX3 reflected by the amplification of IL-10 [33]. Another antiatherogenic mechanism of action of PTX3 is its inhibitory effect on the angiogenic activity of vascular fibroblast growth factor (FGF-2) which is involved in the formation of atherosclerotic plaques by participation in smooth muscle cell proliferation [34].

\section{Summary}

Cardiovascular diseases are leading cause of death in the developed countries; therefore, new methods of prevention, detection and treatment of these civilization diseases are sought. New molecules, such as PTX3, are being studied to be used in the diagnosis and prognosis of cardiovascular diseases. Considering that most of the studies indicating its role as a biomarker of atherosclerotic diseases were carried out on a relatively small groups of patients, and results from few major studies do not coincide with other observations, the role of PTX3 as an atherosclerosis biomarker and its relationship with cardiovascular diseases, remains an interesting direction of exploration and still requires clarification.

\section{REFERENCES}

1. Ross R. Atherosclerosis - An Inflammatory Disease. New England Journal of Medicine. 1999; 340(2): 115-126, doi: 10.1056/ /nejm199901143400207.

2. Hansson GK. Innate and Adaptive Immunity in the Pathogenesis of Atherosclerosis. Circulation Research. 2002; 91(4): 281-291, doi: 10.1161/01.res.0000029784.15893.10.

3. Faxon DP, Fuster V, Libby $P$, et al. American Heart Association. Atherosclerotic Vascular Disease Conference: Writing Group III: pathophysiology. Circulation. 2004; 109(21): 2617-2625, doi: 10.1161/01.CIR.0000128520.37674.EF, indexed in Pubmed: 15173044.

4. Bottazzi B, Doni A, Garlanda C, et al. An integrated view of humoral innate immunity: pentraxins as a paradigm. Annu Rev Immunol. 2010; 28: 157-183, doi: 10.1146/annurev-immunol-030409-101305, indexed in Pubmed: 19968561.

5. Mantovani A, Garlanda C, Bottazzi B, et al. The long pentraxin PTX3 in vascular pathology. Vascul Pharmacol. 2006; 45(5): 326-330, doi: 10.1016/j.vph.2006.08.011, indexed in Pubmed: 17023219.

6. Peri G, Introna M, Corradi D, et al. PTX3, A prototypical long pentraxin, is an early indicator of acute myocardial infarction in humans. Circulation. 2000; 102(6): 636-641, doi: 10.1161/01. cir.102.6.636, indexed in Pubmed: 10931803.

7. Inoue K, Sugiyama A, Reid PC, et al. Establishment of a high sensitivity plasma assay for human pentraxin3 as a marker for unstable angina pectoris. Arterioscler Thromb Vasc Biol. 2007; 27(1): 161-167, doi: 10.1161/01.ATV.0000252126.48375.d5, indexed in Pubmed: 17095712.

8. Latini R, Maggioni AP, Peri G, et al. Lipid Assessment Trial Italian Network (LATIN) Investigators. Prognostic significance of the long pentraxin PTX3 in acute myocardial infarction. Circulation. 2004; 110(16): 2349-2354, doi: 10.1161/01.CIR.0000145167.30987.2E, indexed in Pubmed: 15477419.

9. Suzuki S, Takeishi Y, Niizeki T, et al. Pentraxin 3, a new marker for vascular inflammation, predicts adverse clinical outcomes in patients with heart failure. Am Heart J. 2008; 155(1): 75-81, doi: 10.1016/j.ahj.2007.08.013, indexed in Pubmed: 18082493.

10. Norata GD, Marchesi P, Pulakazhi Venu VK, et al. Deficiency of the long pentraxin PTX3 promotes vascular inflammation and atherosclerosis. Circulation. 2009; 120(8): 699-708, doi: 10.1161/ /CIRCULATIONAHA.108.806547, indexed in Pubmed: 19667236.

11. Garlanda C, Bottazzi B, Bastone A, et al. Pentraxins at the crossroads between innate immunity, inflammation, matrix deposition, 
and female fertility. Annu Rev Immunol. 2005; 23: 337-366, doi: 10.1146/annurev.immunol.23.021704.115756, indexed in Pubmed: 15771574

12. Gewurz $H$, Zhang $X H$, Lint $T$. Structure and function of the pentraxins. Current Opinion in Immunology. 1995; 7(1): 54-64, doi: 10.1016/0952-7915(95)80029-8, indexed in Pubmed: 7772283.

13. Basile A, Sica A, d'Aniello E, et al. Characterization of the promoter for the human long pentraxin PTX3. Role of NF-kappaB in tumor necrosis factor-alpha and interleukin-1 beta regulation. J Biol Chem. 1997; 272(13): 8172-8178, doi: 10.1074/jbc.272.13.8172, indexed in Pubmed: 9079634.

14. Bottazzi B, Vouret-Craviari V, Bastone A, et al. Multimer formation and ligand recognition by the long pentraxin PTX3. Similarities and differences with the short pentraxins C-reactive protein and serum amyloid P component. J Biol Chem. 1997; 272(52): 32817-32823, doi: 10.1074/jbc.272.52.32817, indexed in Pubmed: 9407058.

15. Doni A, Mantovani G, Porta C, et al. Cell-specific regulation of PTX3 by glucocorticoid hormones in hematopoietic and nonhematopoietic cells. J Biol Chem. 2008; 283(44): 29983-29992, doi: 10.1074/jbc.M805631200, indexed in Pubmed: 18703503.

16. Casula M, Montecucco F, Bonaventura A, et al. Update on the role of Pentraxin 3 in atherosclerosis and cardiovascular diseases. Vascul Pharmacol. 2017; 99: 1-12, doi: 10.1016/j.vph.2017.10.003, indexed in Pubmed: 29051088.

17. Jaillon S, Peri G, Delneste $Y$, et al. The humoral pattern recognition receptor PTX3 is stored in neutrophil granules and localizes in extracellular traps. J Exp Med. 2007; 204(4): 793-804, doi: 10.1084/jem.20061301, indexed in Pubmed: 17389238.

18. Bottazzi B, Garlanda C, Salvatori G, et al. Pentraxins as a key component of innate immunity. Curr Opin Immunol. 2006; 18(1): 10-15, doi: 10.1016/j.coi.2005.11.009, indexed in Pubmed: 16343883.

19. Kunes P, Holubcova Z, Kolackova M, et al. Pentraxin 3(PTX 3): an endogenous modulator of the inflammatory response. Mediators Inflamm. 2012; 2012: 920517, doi: 10.1155/2012/920517, indexed in Pubmed: 22577258.

20. Fazzini F, Peri G, Doni A, et al. PTX3 in small-vessel vasculitides: An independent indicator of disease activity produced at sites of inflammation. Arthritis \& Rheumatism. 2001; 44(12): 2841-2850, doi: 10.1002/1529-0131(200112)44:12<2841::aidart472>3.0.co;2-6.

21. Soeki T, Niki T, Kusunose $\mathrm{K}$, et al. Elevated concentrations of pentraxin 3 are associated with coronary plaque vulnerability. J Cardiol. 2011; 58(2): 151-157, doi: 10.1016/j.jjcc.2011.04.005, indexed in Pubmed: 21676590.

22. Savchenko As, Imamura M, Ohashi R, et al. Expression of pentraxin 3 (PTX3) in human atherosclerotic lesions. J Pathol. 2008; 215(1): 48-55, doi: 10.1002/path.2314, indexed in Pubmed: 18220316.

23. Rolph MS, Zimmer S, Bottazzi B, et al. Production of the long pentraxin PTX3 in advanced atherosclerotic plaques. Arterio- scler Thromb Vasc Biol. 2002; 22(5): e10-e14, doi: 10.1161/01. atv.0000015595.95497.2f, indexed in Pubmed: 12006411.

24. Tazaki R, Tanigawa J, Fujisaka T, et al. Plasma Pentraxin3 Level Is Associated With Plaque Vulnerability Assessed by Optical Coherence Tomography in Patients With Coronary Artery Disease. Int Heart J. 2016; 57(1): 18-24, doi: 10.1536/ihj.15-248, indexed in Pubmed: 26673442.

25. Dubin $\mathrm{R}$, Li Y, Ix JH, et al. Associations of pentraxin-3 with cardiovascular events, incident heart failure, and mortality among persons with coronary heart disease: data from the Heart and Soul Study. Am Heart J. 2012; 163(2): 274-279, doi: 10.1016/j. ahj.2011.11.007, indexed in Pubmed: 22305847.

26. Jenny NS, Blumenthal RS, Kronmal RA, et al. Associations of pentraxin 3 with cardiovascular disease: the Multi-Ethnic Study of Atherosclerosis. J Thromb Haemost. 2014; 12(6): 999-1005, doi: 10.1111/jth.12557, indexed in Pubmed: 24628740.

27. Kimura S, Inagaki H, Haraguchi Go, et al. Relationships of Elevated Systemic Pentraxin-3 Levels With High-Risk Coronary Plaque Components and Impaired Myocardial Perfusion After Percutaneous Coronary Intervention in Patients With ST-Elevation Acute Myocardial Infarction. Circulation Journal. 2014: 159-169, doi: 10.1253/circj.cj-13-0329.

28. Guo R, Li Y, Wen J, et al. Elevated plasma level of pentraxin-3 predicts in-hospital and 30-day clinical outcomes in patients with nonST-segment elevation myocardial infarction who have undergone percutaneous coronary intervention. Cardiology. 2014; 129(3): 178-188, doi: 10.1159/000364996, indexed in Pubmed: 25323314.

29. Miyazaki T, Chiuve S, Sacks F et al. Plasma pentraxin 3, a new marker for vascular inflammation, predicts adverse clinical outcomes in patients with heart failure. Am Heart J 2008; 155: 75-81, doi: 10.1371/journal.pone.0094073.

30. Matsubara J, Sugiyama S, Nozaki T, et al. Pentraxin 3 is a new inflammatory marker correlated with left ventricular diastolic dysfunction and heart failure with normal ejection fraction. J Am Coll Cardiol. 2011; 57(7): 861-869, doi: 10.1016/j.jacc.2010.10.018, indexed in Pubmed: 21310324.

31. Napoleone E, di Santo A, Peri G, et al. The long pentraxin PTX3 upregulates tissue factor in activated monocytes: another link between inflammation and clotting activation. J Leukoc Biol. 2004; 76(1): 203-209, doi: 10.1189/jlb.1003528, indexed in Pubmed: 15226367.

32. Norata GD, Marchesi P, Pulakazhi Venu VK, et al. Deficiency of the long pentraxin PTX3 promotes vascular inflammation and atherosclerosis. Circulation. 2009; 120(8): 699-708, doi: 10.1161/ /CIRCULATIONAHA.108.806547, indexed in Pubmed: 19667236.

33. Slusher AL, Mischo AB, Acevedo EO. Pentraxin 3 is an anti-inflammatory protein associated with lipid-induced interleukin 10 in vitro. Cytokine. 2016; 86: 36-40, doi: 10.1016/j.cyto.2016.07.012, indexed in Pubmed: 27450429.

34. Camozzi M, Zacchigna S, Rusnati M, et al. Pentraxin 3 inhibits fibroblast growth factor 2-dependent activation of smooth muscle cells in vitro and neointima formation in vivo. Arterioscler Thromb Vasc Biol. 2005; 25(9): 1837-1842, doi: 10.1161/01. ATV.0000177807.54959.7d, indexed in Pubmed: 16020751 